J. Clin. Chem. Clin. Biochem.

Vol. 16,1978 , pp. $687-692$

\title{
Trends and Aspects in Clinical Chemistry ${ }^{1}$ )
}

\author{
By H. Keller
}

Institut für Klinische Chemie und Hämatologie des Kantons St. Gallen

(Received June 21, 1978)

\begin{abstract}
Summary: This paper first seeks to evaluate current trends in methodology and technology and discusses possible implications for the future of clinical chemistry, whose range and diversity of tasks are carefully defined. It is thought that the remarkable development in the field of immunological methods, in the general sense of the word, will continue for the years to come. One other principle, which it is predicted will play an increasing role, is thermometry for the determination of enthalpy. Similarly, new developments in the fields of bio- and chemoluminescence offer interesting possibilities. The impact of the computer in clinical chemistry is also discussed.
\end{abstract}

Secondly, the double role of clinical chemistry as a diagnostic speciality and as an academic field is analyzed. On the one hand, the need for closer cooperation both with other diagnostic subspecialities and with other medical clinical disciplines is stressed.

In particular, newly organized Departments of Laboratory Medicine encompassing microbiology, cytology, nuclear medicine, toxicology etc. might contribute greatly to interdisciplinary understanding. On the other hand, problems of clinical medicine and of certain areas within biological research should be at the center of interest of the future research-oriented clinical chemist.

\section{Entwicklungstendenzen in der Klinischen Chemie}

Zusammenfassung: Einleitend wird über die sich wandelnden Definitionen des Faches „Klinische Chemie“ referiert. Die Erweiterung der Aufgabengebiete, die darin zum Ausdruck kommt, wird auch von den Entwicklungstendenzen in methodischer und technologischer Hinsicht reflektiert.

Besonders auffallend ist die konstante Zunahme immunologischer Techniken und Methoden, die auch in der Routineanalytik einen ständig wachsenden Anteil einnehmen. Zwei Meßprinzipien, die bisher noch wenig Anwendung in der klinisch-chemischen Analytik finden, verdienen besonderes Interesse: Dies sind die Thermometrie zur Bestimmung der Enthalpie und die zahlreichen Verfahren, die auf Bio- und Chemo-Lumineszenz-Phänomenen beruhen.

Die aktuelle und zukünftige Bedeutung der elektronischen Datenverarbeitung in der klinischen Chemie wird kurz diskutiert.

Manche Probleme im Selbstverständnis des klinischen Chemikers resultieren daraus, daß die klinische Chemie einerseits vielfältige diagnostische Dienstleistungen im Bereich der klinischen Medizin erbringen muß, andererseits aber ein akademisches Grundlagenfach darstellt. Zur Ửberwindung vieler Schwierigkeiten wäre eine engere Kooperation mit den anderen diagnostischen Fächern, aber auch mit den klinischen Disziplinen wünschenswert. Weiter dürfte es von großem Vorteil sein, wenn es gelänge, die Abteilungen für klinische Chemie mit anderen diagnostischen Basisfächern, ż. B. Mikrobiologie, Cytologie, Nuklearmedizin usw. in Departments für Laboratoriumsmedizin zu integrieren. Nịcht nur das interdisziplinäre Verständnis, sondern auch die Kooperation könnte dadurch entscheidend verbessert werden.

Hinsichtlich der Forschungsaktivitäten scheint es ạ der Zeit, sich vermehrt Fragen der klinischen Medizin, aber auch der reinen und angewandten und biologischen Forschung zu widmen.

\footnotetext{
1) Revised from a paper given by the author at the 22 nd. annual meeting of the Swiss Socicty for Clinical Chemistry, $9-10$ th. of June,
} 1978, at Aarau. 


\section{Introduction}

A report on the future of Clinical Chemistry presents certain difficulties, due to the fact that the terms "Clinical Chemistry" and "Clinical Biochemistry" are interpreted in very different ways by different people.

A very early indication to the existence of Clinical Chemistry was given by Shakespeare in the Merchant of Venice "... My blood speaks to you in my veins ..." and our discipline is increasingly learning how to listen. (1)

More recently, less poetic definitions have been given by other authors $(2-8)$.

All definitions agree to the point, that the most important function of our discipline is to support medical diagnosis and control of therapy by chemical analyses. Ideas differ strongly, however, as to whether Cinical Chemistry should encompass other classic "disciplines" and which these might be.

Does Clinical Chemistry pertain to all chemical aspects of human life in health and disease? And does Clinical Chemistry include the explanation of the nature and etiology of diseases, too? Should we make contributions in the field of Clinical Pharmacology, Preventive Medicine and Toxicology?

The definition of Richterich in the first edition (9) of his textbook said, that "... Clinical Chemistry is that medical branch dealing with the development and application of chemical analysis for diagnostic purposes...".

In the last edition (10) it is defined as follows "... Clinical Chemistry is that branch of medicine dealing with development and application of chemical analyses of body fluids and other biological materials for diagnosis, therapy and prophylaxis of diseases ...".

The much broader range of Clinical Chemistry in these definitions is significant.

In the following, I will discuss which definition seems to be the most acceptable for the future, as the role of clinical chemist evolves and new tasks present themselves.

In order to make an extrapolation of the discipline "Clinical Chemistry and Clinical Biochemistry" for the next ten years and in order to get a practicable scheme, I will divide the theme into 6 categories.

\section{General trends of development of methods . and instruments}

In the routine analytic field I believe that photometric methods will continue to predominate in the years to come for the determination of substrates and enzyme activities. For substrates, specific enzymatic reactions will increasingly replace the older, less specific colour tests. This is urgently required for creatinine and phosphate in serum. In the field of bile pigments, especially bilirubin and bilirubinoids, the situation is frustrating. Probably, kine tic methods will replace more and more the end-point tests. This tendency will also prevail in the field of enzymology. Here we can expect new methods for the determination of $\alpha$-amylase, acid phosphatase, lipase and some other enzymes.

Immunological methods are becoming increasingly important in the routine analytical work. In addition to radial immunodiffusion, the nephelometric techniques are also developing, as evidenced by the introduction of laser-nephelometers. In the radioimmunoassay ${ }^{125} \mathrm{I}$ is used as a label in preference to ${ }^{3} \mathrm{H}$ and ${ }^{14} \mathrm{C}$, owing to the short measurement times and the non-specialised character of the scintillators.

To what extent enzyme-immunoassays and fluorescence immunoassays will substitute the radio-immunoassays is a matter of economics and legislation: the more liberal the laws of radiation, the better the prospects for the radio-immunoasssays and vice versa.

It is not possible to predict how long the protein electrophoresis will keep its position despite its doubtful diagnostic relevance. The proposal of Laurell (11) to use the electropherograms only in a qualitative way, in order to decide which, if any individual protein should be quantitatively determined, has not yet been realized in most laboratories.

Newly designed photometers will be smaller than before and the volume of the measuring solution will be reduced. Thanks to the microprocessor we can expect that in a few years each photometer will be equipped with a so-called intelligent terminal.

In photometry, higher resolving power will be possible, as well as better compensation of stray-light-effects. The optimum light source would be a tunable laser but progress on this field seems to be relatively slow.

Also, the flame photometer will be equipped with intelligent terminals. It is surprising that in this field we do not recognise a trend for miniaturization. The development of a flame photometer without a flame or without the unwieldy gas flasks would be desirable. At present, it seems that we need further flame photometry for the determination of group 1A elements of the periodic table.

Ion specific electrodes are still being developed, but not as fast as we assumed ten years ago. The long lag-phases, the possibilities of drifting and the multiplicity of interferences are the reasons why ion specific electrodes are relatively seldom used for routine analysis. Similar problems plague enzyme electrodes.

In the near future some tests will become fast, highly specific and very economic by the exploitation of the modern techniques of immobilized enzymes. 
It seems not very probable that atomic absorption spectrometric methods will expand in the next future. The same is also true for fluorometric techniques.

It is also uncertain as to when the stix techniques will revolutionize our laboratories. It is evident, that very early publication of the Kodak developments may have been untimely, because nobody is able to assess the consequences of these techniques for the future.

\section{Newer aspects of mechanisation and automation}

In the field of mechanisation and automation it seems certain that the continuous flow systems will keep an important place in our laboratories. Three tendencies are significant: The analyzer will become faster, more economical with respect to sample and reagent volume, and the system control will be performed by microprocessors or minicomputers.

Similar developments may be expected with the fast analyzers with rotors.

The situation is unclear for all the other analyzers which are working in a discrete but indiscriminating manner. For longer sample series we may continue with batchwise processing. But with respect to the future, I forecast that analyzers which work in a discrete and discriminating manner will be more favored. Examples of this kind of analyzer are the $\mathrm{GSA}^{2}$ ) of Greiner, Du Pont's ACA, the STAC from Technicon and the PRISMA from LKB. All these analyzers have one handicap, i. e. the low cost/efficiency ratio: Some need relatively high volumes of sample and reagents, some have relatively high costs for implementation, or for operating, or for both.

Most laboratories fulfil more than $90 \%$ of their daily routine task with only 20 different tests. Therefore we need a 20 channel analyzer, which is able to perform these 20 tests identically for each sample in a discrete and discriminating fashion.

For the measurement of radioactivity we are using today mostly partially mechanized systems. New developments for longer series are basing on the "walk-away-automation".

3. Uncertainities and chances of unusual, unconventional and of new methods

Another question is, whether methods and instruments, now in. use only for research and development by

\footnotetext{
2) ACA: Automatic Clinical Analyzer, Firma du Pont de Nemouris, Wilmington, USA

EDP: Electronic Data Processing

GSA: Greiner Selective Analyzer, Firma Greiner, Langenthal, Switzerland

OCR: Optical Character Recognition

PRISMA: Programmable Individual Selective Modular Analyzer Firma Clinicon, Mannheim, Federal Republic of Germany

STAC: Single Test Analyzer with Computer, Firma - Technicon, Inc. Tarrytown, USA
}

laboratories with high standards, could have a broader spectrum of application in the future?

Chromatographic methods e. g. thin layer chromatography, affinity chromatography, gas chromatography in connection with mass spectrometry, and other techniques will be reserved for the larger laboratories.

But there are two sophisticated techniques which have great potential. First of all I would mention thermometry for the measurement of enthalpy of chemical reactions. The reason for this interest is the high universality of applications of enthalpimetric techniques. Already they are installed in con tinuous flow systems for control purposes of technical process. With thermosensors it is also possible to control enzyme catalyzed reactions. E. g. a system has been just published for measuring the hexokinase reaction by its enthalpy (12).

The combination of immobilized enzymes with thermometric techniques for the quick determination of substrates, such as urea, or uric acid and others could be especially fruitful.

This kind of monitoring can also be used for immunological reactions. Certain difficulties still prevent a broader application, but I can imagine that these problems of instrumentation can be solved. Then it could happen - especially in mechanized systems that measurement of enthalpy will replace photometry for a number of analytical methods.

$A$ second and also very interesting field could be the development of methods basing on bioluminescence or chemoluminescence. The extreme sensitivity and the wide range of applications of these types of methods is most impressive. ATP and NAD coupled reactions can be monitored in this way. Also, enzyme activities in the cells, or inside of microorganisms, can be measured using these techniques. Glick has published a very interesting paper about the methods and has made claims that allow for great expectations (13).

\section{Evolution of organizational aspects}

Most of the larger laboratories support their laboratory operations with an EDP system. The better cost/ efficiency ratio in this field will be the reason why computers will further infiltrate medical laboratories.

Instrumentation and the volume of test-programs are decisive for all sample distribution processes.

No method so far for the mechanisation of sample distribution has been completely successful. Some manufacturers have cancelled the development or the production of these systems. It seems that manual processing is superior to the mechanical systems in this area. The centralized sample distribution needs a system for identification. Today mark-sense-cards or bar-code labels are most important. A new, very interesting technique is the OCR-reading. Its special advantage 
is that the OCR-code can be read electronically as well as visually and that it can be written by any type of typewriter. As soon as certain technical difficulties are solved, we can expect that this method of identification will be used by many laboratories.

The discussion about on-line versus off-line connections of instruments to the computer has ceased. The big computer is replaced by many small minicomputers and the intellegent terminals are taking charge of all data pre-processing. Unsolved sofar is the problem of data transport or data-transfer from the laboratory to the ward or the external physician. Also many problems of data storage with fast memory access (important for the laboratory information) remain open, as long as economic limitations exist. We are awaiting new developments in the field of mass memories with better economic aspects.

\section{Necessities for standardization}

Many important problems should be solved in the field of standardization. I would like to raise again the question: which temperature should be used for the determinations of enzyme activities? It is unquestionable that the use of different temperatures in different geographical regions represents a very unsatisfactory situation. Everybody has agreed that optimized methods are preferable, but what are optimized methods?

The quality control is more important and should receive more widespread attention than it does today. The reference materials are inadequate for many problems, especially in the field of immunological tests.

Furthermore we should make more effort in the standardization of terminology, in order to get worldwide consensus.

Precise descriptions and the comparison of methods are not only not standardized, but they are also neglected. In most cases it is not possible to get a clear picture of a method from a publication in one of our journals. However this would be required in order to decide whether a new method should be introduced or a conventional method replaced. For many decades we have had to try each new interesting test in our own laboratory, compare it with present tests, and then decide by ourselves what to do. Standards and definitions for descriptions of methods on an international level would be very useful.

\section{State of Clinical Chemistry, identity as a research and academic discipline}

The situation of Clinical Chemistry in general and academic hospitals, in public and private laboratories is indeed impressive: A great variety of an ever increasing number of tests are available around the clock for diagnosis and for control of therapy. Skilled technicians are working in big laboratories. Expensive instruments, analyzers and machines for electronic data processing are in use. The budget of Clinical Chemistry departments is often much higher than that of other institutions such as pathology or microbiology. But does this all correspond to the importance of clinical chemistry as a medical speciality and as an academic discipline?

A certain amount of doubt seems appropriate: The widespread image of the laboratory wrestling with a constantly increasing number of specimens and tests and the nervous hustling and shuffling of request cards into result sheets has not augmented the reputation of our discipline. Moreover, the prestige of the discipline did not improve when industry began to introduce preprepared reagents. With these testkits, unskilled personel are also able to maintain a satisfactory quality of analytical performance!

The use of the big analyzers has led in many places to a methodological conservatism. Newly developed methods with higher specifity are not introduced, either because the changing of the analyzer is difficult, or because industry does not manufacture a so-called "pack for automation" for this new method. Being afraid of a disruption of the production of results of the day, quantity is prefered over quality. The so-called automation (in fact rather more a mechanisation) has solved problems of quantity, but has created new problems of quality. It is not surprising that certain clinical chemistry departments seem to resemble an industrial factory, where the incoming orders are worked up as quickly and as cheeply as possible. The product of this factory is a result sheet, the single link to the costumer. Contact with him is only accepted in case of complaints.

\section{Research}

The research activities of many laboratories are limited to questions of methodology and work processes. Evaluations of new instruments and new reagent-packs of industry take up a large place in our scientific journals. But this particular topic is not of any interest to our clinical colleagues. Many of them are no longer interested in the progress of Clinical Chemistry in contrast to other diagnostic disciplines. The inability of clinicians to master the development of our discipline will lead to the apostrophe, referring to the Clinical Chemist, as the "little chemist, unable to make essential contributions to medical research". This unfriendly sentence referred to by Astrup (4) in Toronto might overstate the case, but it contains some truth, not only in Scandinavia.

\section{Development}

For a promising and fruitful development of the discipline of Clinical Chemistry it is necessary to reorient the goals: Toward the clinical problems on the 
one hand and to pure and applied biological research on the other.

\section{Clinical problems}

With respect to clinical problems immediately concerning our discipline I would like to give some actual examples:

Without any doubt the analy tical accuracy and precision of many methods are satisfactory for the clinical questions. Another question pertains to the diagnostic validity. And this question, which is much more important, is not systematically or sufficiently examined. Papers in this field are published mainly by Scandinavian and US authors. The well known book of Galen \& Gambino (14) "Beyond normality" has had a world wide succes and has stimulated a great interest in the methods for calculating the diagnostic value of a laboratory test. These methods are based on the Bayes Theorem, Shannon's information theory, statistical decision techniques, especially the discriminant analysis, multivariate analysis and factor analysis. These methods should also become tools of the modern clinical chemist.

However, the goal should not only be the production and transfer of numbers; the critical evaluation and interpretation also comes within our scope. Interpretation with respect to the dynamic steady states, the circadian and intraindividual rhythms, the actual status of the disease and its treatment: these all are challenges to the clinical chemist. In this connection we necessarily need very close cooperation with our clinical colleagues of all departments.

Thus borderlines of the disciplines are crossed and an interdisciplinary dialogue will have to take place. These contacts need to be established not only with specialist doctors, but also with the toxicological laboratories of industry, preventive medicine and others.

In the field of control of drug effects and side effects we could cooperate with clinical pharmacology. The good contact with the hematological departments should be extended also to histology, cytology and other morphological disciplines.

\section{Biological research}

Morover the clinical chemist should be more active in the field of pure and applied biological research: cells and cell cultures are new and very important materials for our laboratories. The diagnostic use of tissue cultures might be a new avenue for analysis. The sensitivity of malignant cells to certain chemical compounds could be investigated in our laboratories. A beginning has been made by the estrogen and gestagen receptors. This technique is of a great interest to all clinical chemical laboratories and should be intensively cultivated in the near future.

Another field recently discovered by Clinical Chemistry is coagulation research. With the newly developed, socalled chromogenic substrates we could make a substantial contribution to research and diagnosis in the field of coagulopathias. But clearly, the number of interested clinical chemist is very small so far.

\section{Conclusions}

It seems that the future of clinical chemistry is not dependent on faster and faster automatic machines: neither is it dependent on simpler and simpler test kits, or on an ever increasing number of tests. It depends on our own attitude to our discipline. If our clinical colleagues qualify clinical chemistry as a pure technical speciality and if we accept this qualification, then we will be, in the future, no more than paramedical technicians.

One of the arguments against the postulated expansion of our discipline might be that medical research is extremely expensive today. But exactly this point is an argument for our case: The clinical chemists have at their disposal a great weal th of knowledge in the basic sciences. They have great technological experience, well qualified personnel available and very expensive instrumentation. The same is true in many places for the other diagnostic disciplines e. g. hematology, cytology and microbiology.

The clear separation of these disciplines into independent kingdoms, as is usual in Central Europe, prevents the utilization of all technical and intellectual potentials.

In many US and Scandinavian hospitals these disciplines are united within one "Department for Laboratory Medicine". And these departments of laboratory medicine are more open and more available for cooperation with the clinicians. Through the common use of many installations like mechanical shops, library, electronic data processing units and so on, the overall cost can be decreased. And the close cooperation of all diagnostic disciplines with all clinical departments will lead to a better understanding of all concerned with patient health care.

Whatever we intend and whatever we do, the future is dependent on our own philosophy, and on our own ability to master more challenging problems. 


\section{References}

1. Seligson, D. (1972), $8^{\text {th }}$ Int. Congr. Clin. Chem. Copenhagen 1972.

2. Sanz, M. C. \& Lous, P. (1971), IFCC News letter No. 6, 1

3. Eldjarn, L., Jellum, E. \& Stokke, O. (1975), Clin. Chem. $21,63-66$.

4. Astrup, P. (1975), Clin. Chem. 21, 1709-1715.

5. American Association of Clinical Chemists: Article I. Sect. 2, "Guide to Ethics", August 1975.

6. Shafrir, E. (1977), Clin. Chem. 23, 1961-1963.

7. Delbrück, A. (1978), Chemische Rundschau Nr. 15, 1-2.

8. Colombo, J. P. (1978), Chemische Rundschau Nr. 22, 1.
9. Richterich, R. (1964), Klinische Chemie, 1. Auflage, Karger-Verlag, Basel.

10. Richterich, R. \& Colombo, J. P. (1978), Klinische Chemie, 4. Auflage, Karger-Verlag, Basel.

11. Laurell, C. B. (1973), Clin. Chem. 19, 99-102.

12. Bowers, L. D. \& Carr, P. W. (1976), Clin. Chem. 22, 1427-1433.

13. Glick, D. (1977), Clin. Chem. 23, 1465-1471.

14. Galen, R. S. \& Gambino, S. R. (1975), Beyond Normality, J. Wiley and Sons, New York.

Prof. Dr. Dr. H. Keller Institut für Klinische Chemie und Hämatologie

Frohbergstraße 3

CH-9000 St. Gallen 